\title{
Primary pulmonary malignant fibrous histiocytoma: case report and literature review
}

\author{
Xiongfei Li ${ }^{1 *}$, Renwang Liu ${ }^{1 *}$, Tao Shi ${ }^{2 *}$, Shangwen Dong ${ }^{3}$, Fan Ren ${ }^{1}$, Fan Yang ${ }^{1}$, Dian Ren ${ }^{1}$, Haiyang \\ Fan $^{1}$, Sen Wei ${ }^{1}$, Gang Chen ${ }^{1}$, Jun Chen ${ }^{1,4}$, Song Xu ${ }^{1,4}$ \\ ${ }^{1}$ Department of Lung Cancer Surgery, ${ }^{2}$ Department of Pathology, ${ }^{3}$ Department of Cardiothoracic Surgery, ${ }^{4}$ Tianjin Key Laboratory of Lung Cancer \\ Metastasis and Tumor Microenvironment, Lung Cancer Institute, Tianjin Medical University General Hospital, Tianjin 300052, China \\ *These authors contributed equally to this work. \\ Correspondence to: Jun Chen, MD, PhD. Department of Lung Cancer Surgery, Lung Cancer Institute, Tianjin Medical University General Hospital, \\ No. 154 Anshan Road, Heping District, Tianjin 300052, China. Email: huntercj2004@yahoo.com; Song Xu, MD, PhD. Department of Lung Cancer \\ Surgery, Lung Cancer Institute, Tianjin Medical University General Hospital, No. 154 Anshan Road, Heping District, Tianjin 300052, China. \\ Email: xusong198@hotmail.com.
}

\begin{abstract}
Malignant fibrous histiocytoma (MFH) is an aggressive soft tissue sarcoma known to occur in various organs. Primary MFH arising in the lung is quite rare. Herein we report a case of a 61-year-old male with primary pulmonary $\mathrm{MFH}$ and explore the underlying molecular mechanisms by next-generation sequencing (NGS). Five gene mutations in TSC2, ARID1B, CDK8, KDM5C and CASP8 were detected, and the mTOR inhibitor might be an effective treatment for this patient. In addition, we reviewed the scientific literature of approximately 23 primary pulmonary MFH case reports since 1990 and summarized the clinical features and prognosis of this rare pulmonary malignant tumor.
\end{abstract}

Keywords: Malignant fibrous histiocytoma (MFH); sarcoma; surgery; sequencing

Submitted Mar 03, 2017. Accepted for publication Jul 03, 2017.

doi: $10.21037 /$ jtd.2017.07.59

View this article at: http://dx.doi.org/ 10.21037/jtd.2017.07.59

\section{Introduction}

Malignant fibrous histiocytoma (MFH) is an aggressive soft tissue sarcoma originating from mesenchymal tissues (1). It is one of the most common soft tissue sarcomas in adults and can also affect juveniles (1). Although MFH can develop in various organs, it most commonly occurs in the extremities and the retroperitoneal space of the abdominal cavity (2). However, primary MFH arising in the lung is rare (3). Since the first case reported in 1979, there have been approximately 36 reported cases of primary pulmonary MFH. Primary pulmonary MFH is highly malignant, and there are no optimal or consensus treatment strategies (4). In order to find a better treatment and improve the survival rate, we performed next-generation DNA sequencing (NGS) of MFH tissue from a 61-year-old male with primary pulmonary MFH. In addition, we summarized the clinical features and prognosis of this rare pulmonary malignant tumor based on the published literature (4-23).

\section{Case presentation}

A 61-year-old male with a 40-year heavy smoking history was admitted with chief complaints of an intermittent cough and blood expectoration for 10 days. Computed tomography (CT) scans revealed an $8 \mathrm{~cm} \times 7 \mathrm{~cm} \times 5 \mathrm{~cm}$ mass in the right upper lobe with large lymph nodes present in the hilum and mediastinum (Figure 1). Subsequent physical examination revealed reduced respiratory sounds over the right upper lung field. Laboratory tests revealed a high expression of neuron-specific enolase (NSE) $(19 \mu \mathrm{g} / \mathrm{L}$, range: $0-16.3 \mu \mathrm{g} / \mathrm{L}$ ), aspartate aminotransferase (AST 47 U/L, range: 15-46 U/L), creatine kinase (CK 180 U/L, range: $30-170 \mathrm{U} / \mathrm{L})$, creatine kinase-isoenzyme (CKMB $27 \mathrm{U} / \mathrm{L}$, range: $0-24 \mathrm{U} / \mathrm{L})$ and urea $(8.0 \mathrm{mmol} / \mathrm{L}$, range $2.5-7.1 \mathrm{mmol} / \mathrm{L})$. Radiological tests revealed no 

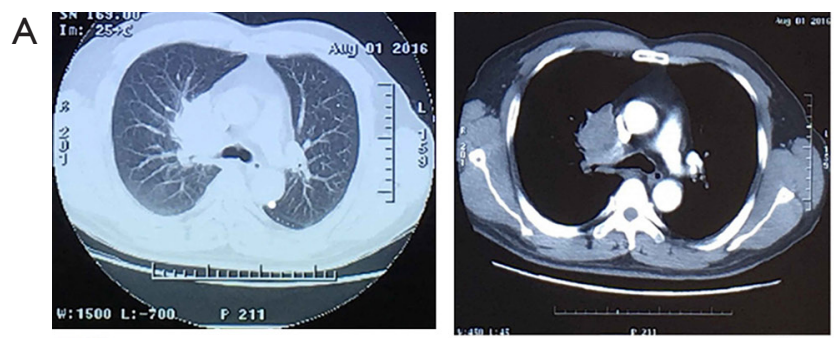

\section{B}
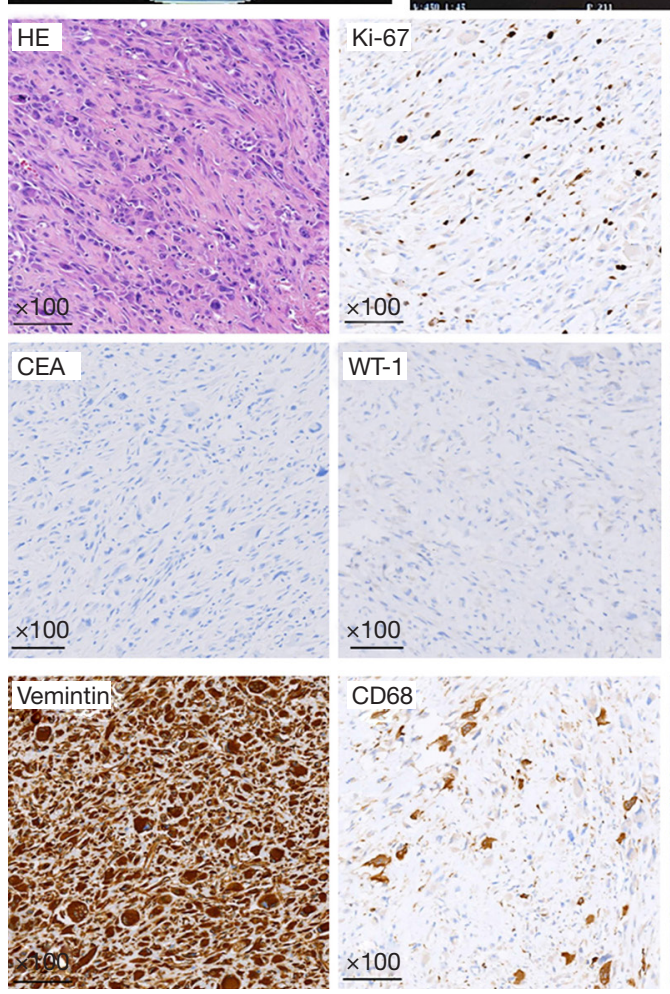

$$
\text { Desmin }
$$
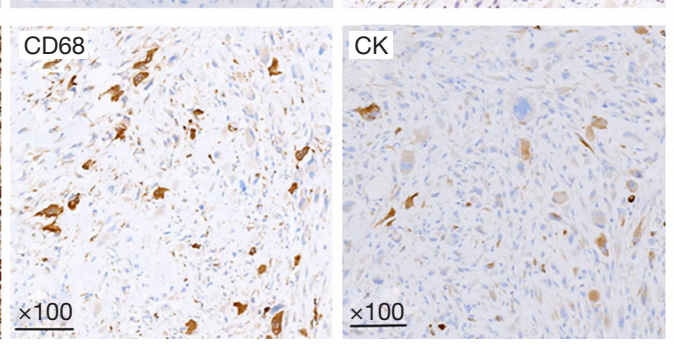
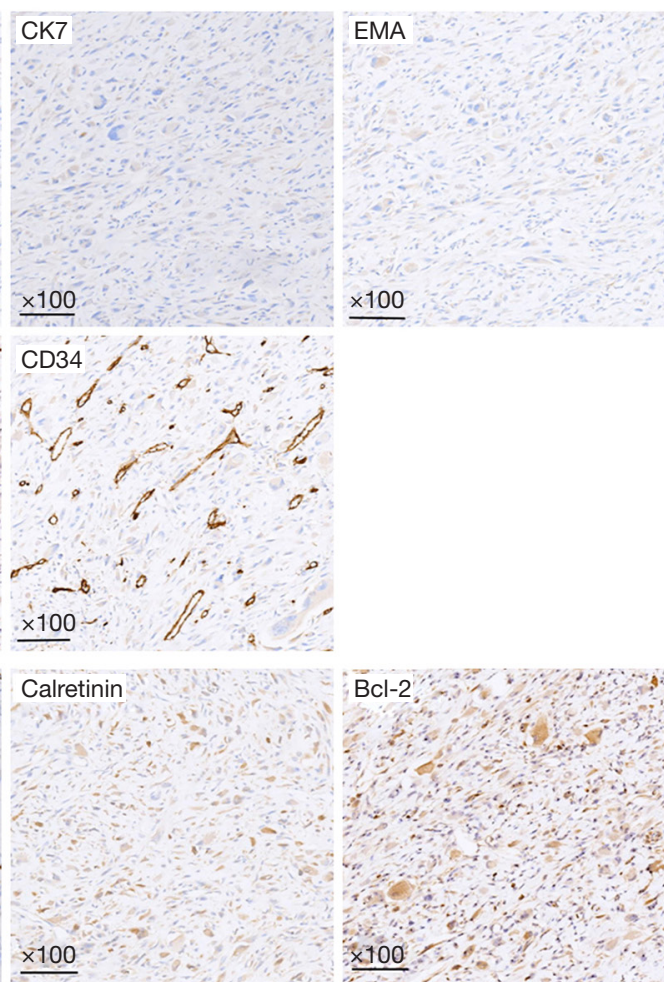

Figure $1 \mathrm{CT}$ images, H\&E and immunohistochemical staining results. (A) Chest CT shows an $8 \mathrm{~cm} \times 7 \mathrm{~cm} \times 5 \mathrm{~cm}$ mass in the right upper lobe with large lymph nodes present in the hilum and mediastinum; (B) H\&E staining shows irregularly shaped infiltrating cells with abnormal nuclei and prominent nucleoli. IHC staining shows diffuse positivity for vimentin and partial positivity for CD68, CK, CD68, calretinin and Bcl-2 with a Ki67 index of approximately 10\% and negativity for desmin, CK7, EMA, CEA, WT-1, CD34 and CD30.

significant abnormalities in the abdomen, brain or bone. A bronchoscopy was performed of the interlobar crest of the right upper lobe and rapid on-site evaluation (ROSE) revealed necrosis and morphologically heterogeneous cells. Histopathological examination further showed evidence of squamous metaplasia with moderate atypical hyperplasia, including lymphocyte and neutrophil infiltration.

Following this initial examination, the patient underwent a right upper lobectomy and systemic lymphadenectomy with bronchial sleeve resection and subsequent reconstruction of the pulmonary artery and superior vena cava. Immunohistochemical staining of tumor tissue demonstrated positivity for vimentin,
CK (Cytokeratin), CD68, calretinin and Bcl-2 with a Ki-67 proliferative index of approximately $10 \%$. In contrast, tumors were deemed negative for desmin, CK7, epithelial membrane antigen (EMA), carcinoembryonic antigen (CEA), wilm's tumor-1 (WT-1), CD34 and CD30 (Figure 1). Paratracheal lymph nodes were positive for metastasis, and the patient was given a diagnosis of $\mathrm{MFH}$.

To explore the underlying molecular mechanisms and their potential therapeutic relevance, we utilized targeted next-generation sequencing (NGS) to detect driver mutations in tumor DNA (tDNA) with matched white blood cell (WBC) DNA as a control (sequencing depth 
$>1,000 \times$; Beijing USCI Medical Laboratory Co., Ltd., China). A panel of 549 tumor-related genes was subjected to NGS (Supplementary method, Figure S1). The sequencing results identified five genes that each contained a single missense mutation (Figure 2). No copy number variation or gene translocation events were detected. Among the identified mutated genes, TSC2 was detected at the highest frequency (15.64\%).

\section{Discussion}

Since the first introduction in 1979, and the origin of MFH was always an enigma. Until $2012 \mathrm{MFH}$ was declassified as a formal diagnostic entity and renamed as an undifferentiated pleomorphic sarcoma by the World Health Organization (WHO). This new terminology has been supported by a compelling body of evidence over the last decade to suggest that $\mathrm{MFH}$ is an aggressive soft tissue sarcoma originating from mesenchymal cells (1). MFH most frequently occurs in the extremities or retroperitoneal abdominal cavity (2), whereas pulmonary $\mathrm{MFH}$ is uncommon, accounting for less than $0.2 \%$ of pulmonary tumors (3).

We provide a literature review of primary pulmonary MFH patients as summarized in Table 1. Since 1990 there have been 20 published case reports of 23 primary pulmonary MFH patients (4-23). We have retrieved this literature and summarized the clinical features of these cases together with the case reported in the current study (Table 1). Coughing, hemoptysis and dyspnea were the most common symptoms, whereas shortness of breath, chest pain and weight loss were less frequently reported. In addition, 3 patients $(13.04 \%)$ were asymptomatic such that $\mathrm{MFH}$ was discovered by CT scan during the course of a regular examination. There were more male $\mathrm{MFH}$ patients than female patients (14 vs. 9), and patient age ranged from 9 to 86 years old with a mean age of $52.87 ; 73.91 \%$ of these patients were between 40 and 80 years old at the time of diagnosis. Of these 23 patients, 3 were smokers, 5 were nonsmokers, and the remaining 15 had no specific record of smoking history. Thus, there is no obvious correlation of cigarette smoking with pulmonary MFH morbidity. There was no significant difference between the left and right lungs for MFH morbidity (30 vs. 31).

The documented information regarding tumor size is variable. One $\mathrm{MFH}$ patient with a tumor diameter of $1.7 \mathrm{~cm}$ lived for 108 months and still had no disease symptoms (3), while another patient with a tumor diameter of $11 \mathrm{~cm}$ died six months after diagnosis (19). This comparison suggests that MFH patients with smaller tumors have a relatively good prognosis, although the overall prognosis for the disease is poor.

In general, the overall survival of reported cases ranged from 0 to more than 168 months. For these 23 patients, 5 patients did not receive any treatment and 2 patients received only chemotherapy or radiotherapy. In total, 15 patients underwent surgical resection, including 11 lobectomies, 3 pneumonectomies and 1 tumorectomy. In these 15 surgeries, 6 combined resection with neoadjuvant or adjuvant chemotherapy. Of these, 4 patients survived less than 12 months, 2 patients survived more than 12 months. Complete resection of tumors with systematic lymph node dissection is thought to contribute to the survival of patients with primary pulmonary MFH (4).

The diagnosis of primary pulmonary $\mathrm{MFH}$ is typically a multi-step process. First, a complete extrathoracic evaluation is made to confirm that $\mathrm{MFH}$ originated in the lung. Imaging techniques such as PET-CT are also utilized to arrive at a diagnosis of pulmonary $\mathrm{MFH}$, which must be ultimately confirmed by histological examination. Histological sections can be obtained from preoperative puncture, tracheoscopic biopsy or postoperative tumor tissue. Maeda et al. (4) report that histological analysis for preoperative diagnosis is rare and only $4 \%$ of reported cases were histologically diagnosed before surgery. There are no specific immunohistochemical markers for MFH, however, other sarcomas with similar microscopic findings have be excluded with immunohistochemical staining. Desmin, actin, vimentin, keratin, and neurogenic tumors are commonly stained for the differential diagnosis. In the current case, no abnormalities other than the pulmonary mass were found by brain MRI, enhanced CT of abdomen and bone ECT examinations. The patient was then subjected to surgical resection, and subsequent immunohistochemical staining confirmed the diagnosis of $\mathrm{MFH}$.

Molecular mechanisms responsible for primary pulmonary MFH formation and progression are mainly unknown. To explore possible underlying mechanisms, we performed NGS on postoperative tumor tissue. The resulting profiling data revealed five mutations in the TSC2, ARID1B, CDK8, $K D M 5 C$ and CASP 8 genes. The mutation distribution diagrams of these genes from TCGA and highlighted in Figure 2. Among these, the mutation frequency of TSC2 was $15.64 \%$, which encodes a M280V missense mutation. The TSC2 gene encodes tuberin, which is known to form heterodimers with hamartin (24). The tuberin/hamartin 


\begin{tabular}{lcc}
\hline Gene & Amino acid change & Frequency(\%) \\
\hline TSC2 & M280V missense mutation & 15.64 \\
ARIDIB & A329G missense mutation & 3.28 \\
CDK8 & A68E missense mutation & 2.17 \\
KDM5C & R614Q missense mutation & 1.94 \\
CASP8 & D217E missense mutation & 1.68 \\
\hline
\end{tabular}
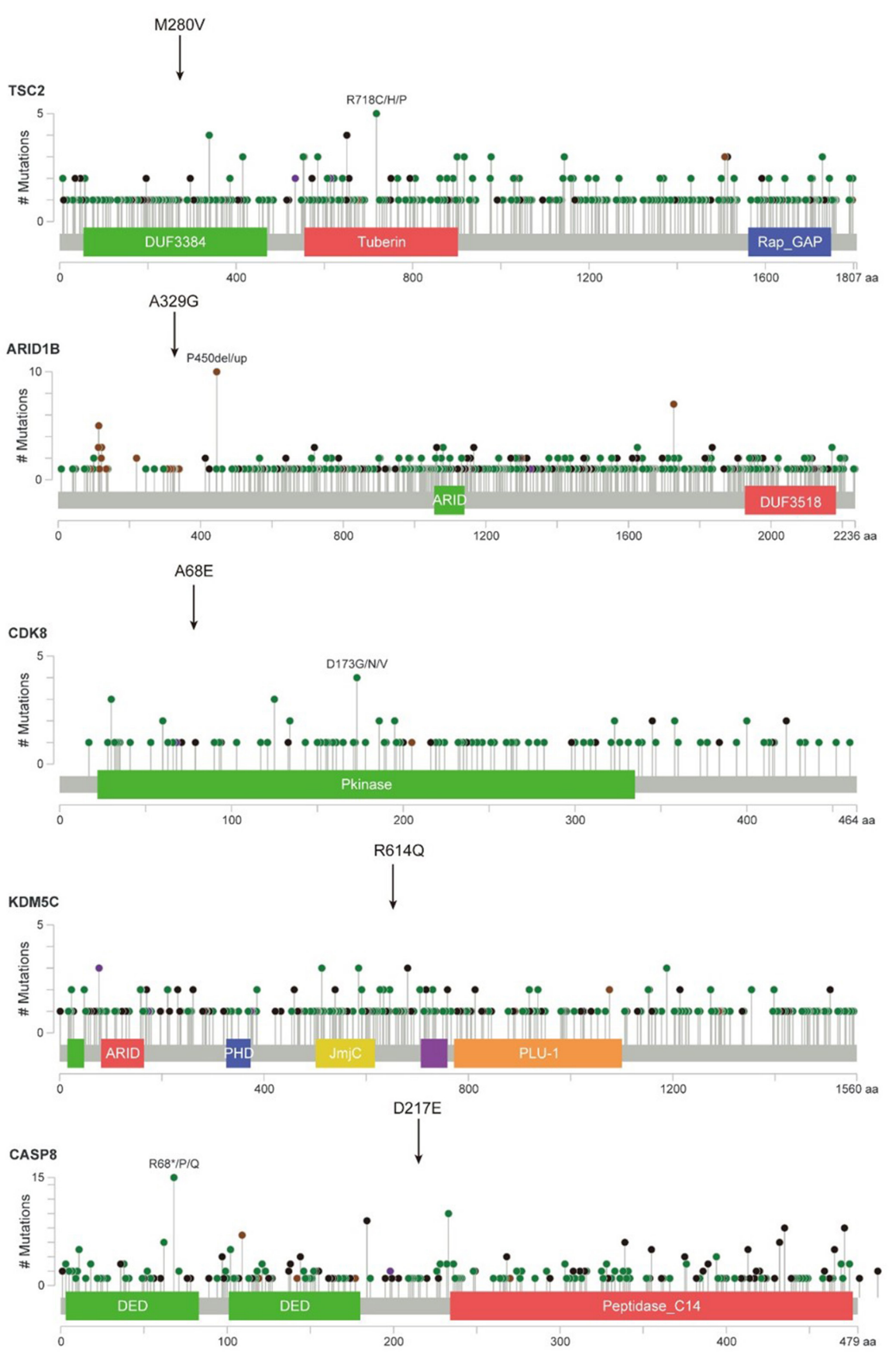

Figure 2 Gene mutation analysis results and corresponding data from The Cancer Genome Atlas (TCGA). The identified missense mutations in TSC2, ARID1B, CDK8, KDM5C and CASP8 are overlaid with the mutation distribution diagrams of these genes from TCGA and highlighted with black arrows. 
Table 1 Literature review of primary pulmonary MFH

\begin{tabular}{|c|c|c|c|c|c|c|c|c|c|c|c|}
\hline Case & Reference & $\begin{array}{c}\text { Age } \\
\text { (years) }\end{array}$ & Sex & $\begin{array}{l}\text { Smoke } \\
\text { status }\end{array}$ & Site & Size $(\mathrm{cm})$ & $\begin{array}{l}\text { Symptoms at the } \\
\text { admission }\end{array}$ & Treatment & LN & $F / U$ & $\begin{array}{l}\text { Survival } \\
\text { (m) }\end{array}$ \\
\hline 1 & $\begin{array}{l}\text { Patel } \\
\text { et al. (5) }\end{array}$ & 86 & M & NA & RLL & $\begin{array}{l}9.6 \times 8.9 \\
\times 7.6\end{array}$ & $\begin{array}{l}\text { Cough, dyspnea, } \\
\text { and increasing } \\
\text { weakness }\end{array}$ & Lobectomy & NEG & NED & 6 \\
\hline 2 & Li et al. (7) & 80 & $\mathrm{~F}$ & NA & RUL & 8 & Cough & None & NA & DOD & 1.5 \\
\hline 4 & $\begin{array}{l}\text { Thomas } \\
\text { et al. (6) }\end{array}$ & 47 & M & No & RUL & NA & $\begin{array}{l}\text { Swelling on the } \\
\text { gingiva }\end{array}$ & $\begin{array}{l}\text { Chemotherapy/ } \\
\text { XRT }\end{array}$ & POS & DOD & 2 \\
\hline 5 & $\begin{array}{l}\text { Tsangaridou } \\
\text { et al. (9) }\end{array}$ & 54 & M & Yes & $\begin{array}{l}\text { LUL/ } \\
\text { LLL }\end{array}$ & NA & NA & Pneumonectomy & POS & AWD & 168 \\
\hline 8 & $\begin{array}{l}\text { Noh } \\
\text { et al. (11) }\end{array}$ & 58 & $\mathrm{~F}$ & No & RUL & $5 \times 4$ & NA & Lobectomy/XRT & NEG & NED & 5 \\
\hline 9 & $\begin{array}{l}\text { Wang } \\
\text { et al. (12) }\end{array}$ & 86 & M & No & LLL & $9 \times 15$ & $\begin{array}{l}\text { Exertional dyspnea } \\
\text { and poor appetite }\end{array}$ & None & NA & DOD & 2 \\
\hline 10 & $\begin{array}{l}\text { Alhadab } \\
\text { et al. (13) }\end{array}$ & 56 & M & NA & $\begin{array}{l}\text { LUL/ } \\
\text { LLL }\end{array}$ & NA & $\begin{array}{l}\text { Cough and shortness } \\
\text { of breath }\end{array}$ & None & NA & DOD & 4 \\
\hline 11 & $\begin{array}{l}\text { Herrmann } \\
\text { et al. (14) }\end{array}$ & 57 & M & No & RUL & $13 \times 8$ & Car accident & Lobectomy & NA & NED & 12 \\
\hline 15 & $\begin{array}{l}\text { Nistal } \\
\text { et al. (16) }\end{array}$ & 12 & $\mathrm{~F}$ & No & LUL & $7 \times 6 \times 5$ & $\begin{array}{l}\text { Chest pain, fatigue, } \\
\text { non-productive } \\
\text { cough and weight } \\
\text { loss }\end{array}$ & $\begin{array}{l}\text { Lobectomy/ } \\
\text { chemotherapy }\end{array}$ & NA & AWD & 5 \\
\hline 16 & $\begin{array}{l}\text { Gómez- } \\
\text { Román } \\
\text { et al. (20) }\end{array}$ & 61 & M & NA & RUL & 3 & NA & Tumorectomy & NA & NED & 9 \\
\hline
\end{tabular}

Table 1 (continued) 
Table 1 (continued)

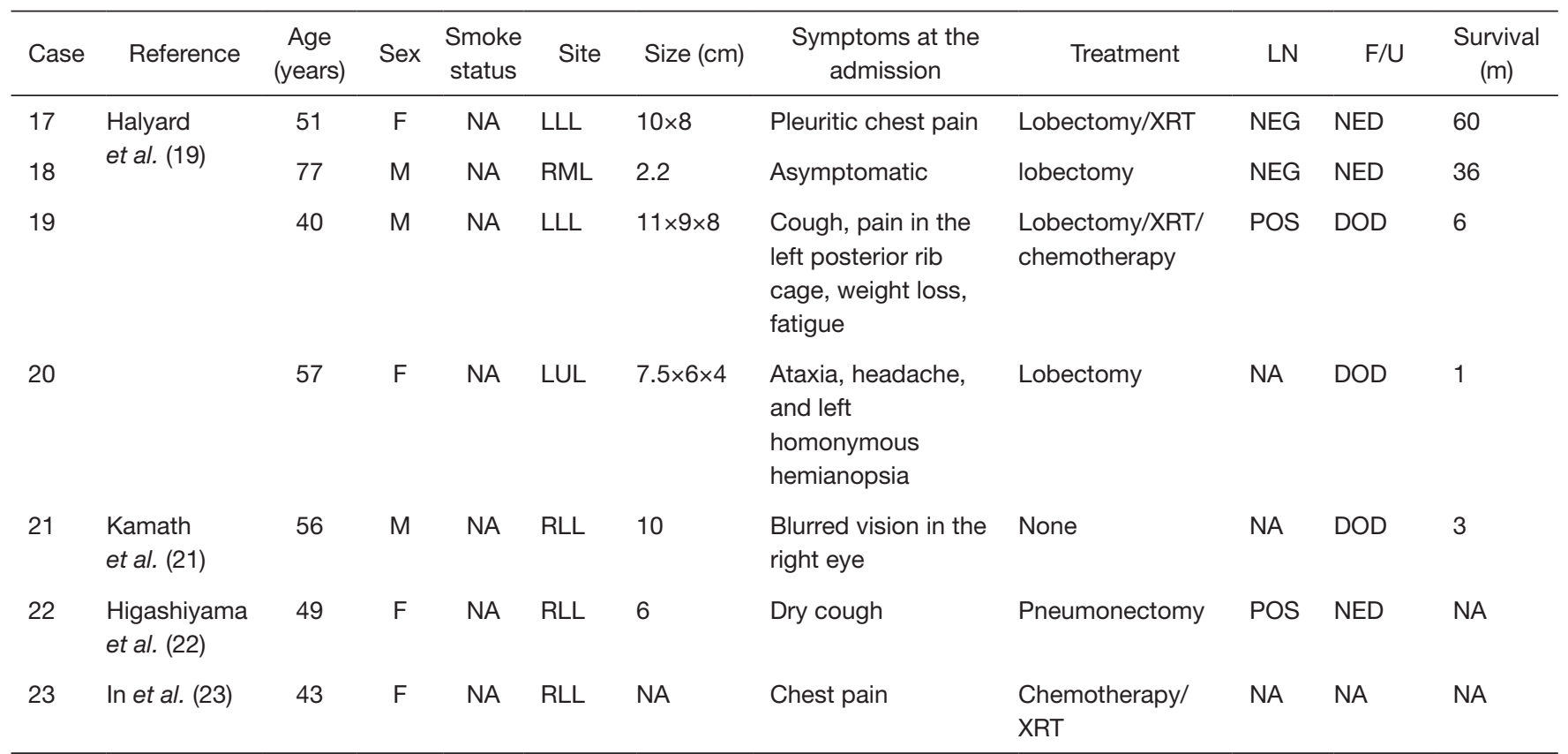

MFH, malignant fibrous histiocytoma; LUL, left upper lobe; LLL, left lower lobe; RUL, right upper lobe; RML, right middle lobe; RLL, right lower lobe; NA, not available; XRT, radiotherapy; F/U, follow up; DOD, dead of MFH disease; AWD, alive with MFH disease; NED, no evidence of MFH disease; DNED, dead no evidence of MFH disease; m, month.

heterodimer inhibits the Rheb GTPase, leading to inactivation of the Rheb/mTOR/p70S6K pathway, which is a major regulator of cell growth and proliferation (24) Thus, deleterious mutations in TSC2 result in activation of the mTOR pathway, abnormal cell growth and increased proliferation. In non-small cell lung cancer, a previous study reported that targeting TSC2 can inhibit cancer cell growth (25). Therefore, we postulate that the TSC2 mutation identified here might be functionally involved in primary pulmonary MFH occurrence or progression, and mTOR inhibitors, such as everolimus, might be efficacious for some MFH patients.

In conclusion, based on the published literature reviewed here, $\mathrm{MFH}$ is insensitive to both chemotherapy and radiotherapy. Thus, once the diagnosis is confirmed, complete surgical resection is necessary. Targeted therapy using mTOR inhibitors might be a promising future treatment for this rare disease.

\section{Acknowledgements}

Funding: This work was supported by grants from the National Natural Science Foundation of China (81301812,
81172233), Specialized Research Fund for the Doctoral Program of Higher Education (20131202120004), Science \& Technology Foundation for Selected overseas Chinese scholar Ministry of personnel of China, Science \& Technology Foundation for Selected overseas Chinese scholar Bureau of personnel of China Tianjin, Tianjin Key Project of Natural Science Foundation (17JCZDJC36200), Tianjin Educational Committee Foundation (20120117) and Tianjin Medical University General Hospital Young Incubation Foundation (ZYYFY2015015).

\section{Footnote}

Conflicts of Interest: The authors have no conflicts of interest to declare.

Informed Consent: Written informed consent was obtained from the patient for publication of this manuscript and any accompanying images.

\section{References}

1. O'brien JE, Stout AP. Malignant fibrous xanthomas. 
Cancer 1964;17:1445-55.

2. Weiss SW, Enzinger FM. Malignant fibrous histiocytoma: an analysis of 200 cases. Cancer 1978;41:2250-66.

3. Yousem SA, Hochholzer L. Malignant fibrous histiocytoma of the lung. Cancer 1987;60:2532-41.

4. Maeda J, Ohta M, Inoue $M$, et al. Surgical intervention for malignant fibrous histiocytoma of the lung: report of a case. Surg Today 2007;37:316-9.

5. Patel DP, Gandhi YS, Sommers KE, et al. Primary pulmonary malignant fibrous histiocytoma. Case Rep Pulmonol 2015;2015:381276.

6. Thomas ME, Koshi R. Electron microscopy in the diagnosis of malignant fibrous histiocytoma of the lung presenting as metastasis to the maxillary gingiva. Int J Oral Maxillofac Surg 2013;42:99-101.

7. Li JQ, Zhang JR, Li L, et al. Inflammatory malignant fibrous histiocytoma of the lung combined with fungal infection. Chin Med J (Engl) 2013;126:4379.

8. Jeon YH, Park KS. Successful management of a recurrent primary malignant fibrous histiocytoma of the lung: report of a case. Korean J Thorac Cardiovasc Surg 2012;45:345-7.

9. Tsangaridou I, Papamihalis G, Stathopoulos K, et al. Primary malignant fibrous histiocytoma of the lung: a case report. Case Rep Med 2010;2010:389692.

10. Maitani F, Fujimori S, Hayashi Y, et al. A case of juvenile primary pulmonary malignant fibrous histiocytoma. Tokai J Exp Clin Med 2010;35:130-2.

11. Noh HW, Park KJ, Sun JS, et al. Primary pulmonary malignant fibrous histiocytoma mimics pulmonary artery aneurysm with partial thrombosis: various radiologic evaluations. Eur Radiol 2008;18:1653-7.

12. Wang CS, Tsai KB, Tsai JR, et al. Primary malignant fibrous histiocytoma of the lung: a case report. Kaohsiung J Med Sci 2003;19:428-32.

13. Alhadab T, Alvarez F, Phillips NJ, et al. Malignant fibrous histiocytoma of the lung presenting as bronchial obstruction in a heart transplant recipient. J Heart Lung Transplant 2002;21:1140-3.

14. Herrmann BL, Saller B, Kiess W, et al. Primary malignant fibrous histiocytoma of the lung: IGF-II producing tumor induces fasting hypoglycemia. Exp Clin Endocrinol Diabetes 2000;108:515-8.

15. Fujita Y, Shimizu T, Yamazaki K, et al. Bronchial brushing cytology features of primary malignant fibrous histiocytoma of the lung. A case report. Acta Cytol 2000;44:227-31.

16. Nistal M, Jimenez-Heffernan JA, Hardisson D, et al. Malignant fibrous histiocytoma of the lung in a child. An unusual neoplasm that can mimick inflammatory pseudotumour. Eur J Pediatr 1997;156:107-9.

17. Barbas CS, Capelozzi VL, Takagaki TY, et al. Primary malignant fibrous histiocytoma of the lung. Report of a case with bronchial brushing cytologic features. Acta Cytol 1997;41:919-23.

18. Shah SJ, Craver RD, Yu LC. Primary malignant fibrous histiocytoma of the lung in a child: a case report and review of literature. Pediatr Hematol Oncol 1996;13:531-8.

19. Halyard MY, Camoriano JK, Culligan JA, et al. Malignant fibrous histiocytoma of the lung. Report of four cases and review of the literature. Cancer 1996;78:2492-7.

20. Gómez-Román JJ, Val-Bernal JF. A case of malignant fibrous histiocytoma of the lung arising as a third primary tumor. Thorac Cardiovasc Surg 1996;44:321-3.

21. Kamath SV, Tenreiro-Picon OR, Ragland RL, et al. Brain metastases from primary lung malignant fibrous histiocytoma: a case report. J Neuroimaging 1995;5:133-4.

22. Higashiyama M, Doi O, Kodama K, et al. Successful surgery of malignant fibrous histiocytoma in the lung with gross extension into the right main pulmonary artery. Thorac Cardiovasc Surg 1993;41:73-6.

23. In KH, Byun HJ, Kang KH, et al. A case of pulmonary malignant fibrous histiocytoma associated with pulmonary artery obstruction. Korean J Intern Med 1990;5:79-82.

24. Benvenuto G, Li S, Brown SJ, et al. The tuberous sclerosis-1 (TSC1) gene product hamartin suppresses cell growth and augments the expression of the TSC2 product tuberin by inhibiting its ubiquitination. Oncogene 2000;19:6306-16.

25. Kwiatkowski DJ. Tuberous sclerosis: from tubers to mTOR. Ann Hum Genet 2003;67:87-96.
Cite this article as: Li X, Liu R, Shi T, Dong S, Ren F, Yang F, Ren D, Fan H, Wei S, Chen G, Chen J, Xu S. Primary pulmonary malignant fibrous histiocytoma: case report and literature review. J Thorac Dis 2017;9(8):E702-E708. doi: 10.21037/jtd.2017.07.59 
Supplementary method

Next-generation sequencing

The panel was used to sequence all exons of 549 tumorrelated genes mutations simultaneously (Figure S1). The Qubit dsDNA assay to make sure that genomic DNA was $100 \mathrm{ng}$. Adjust the volume to a total of $100 \mu \mathrm{L}$ using $1 \times$ for fraw EDTA and transfor to a Covaris microTUBE verage DNA fragment size is 180-220 bp, followed by hybridization with the capture probes baits, hybrid selection with magnetic beads, and PCR amplification. A bioanalyzer high-sensitivity DNA assay was then used to assess the quality and size range. Available indexed samples were then sequenced on a Nextseq (lllumina, Sar
NEXT SEQ 500 runs were processed with flexbar software (version 2.7.0, https://sourceforge.net/projects/flexbar/) to generate clean fastq data, trim adapter sequences, and filter and remove poor quality reads. Then clean fast data were aligned to hg19 (GRCH37) assembly by using 7.7.12anpe (Burrows Wheeler Aligner sottware versio (ites/), and PCR (polymerase chain were removed by MarkDuplicates tool in Pienlicates (version 1.124, http//broedinstitute gith All variants were annotated using ANNOVAR (versio 20160201, http://annovar.openbioinformatics.org/en/ latest $/$ ). Variation frequency $(>0.5 \%)$ was used to eliminate erroneous base calling and generate final mutations, and nanual verification was performed using IGV (Intergrative broadinstitute.org/software/igv/).

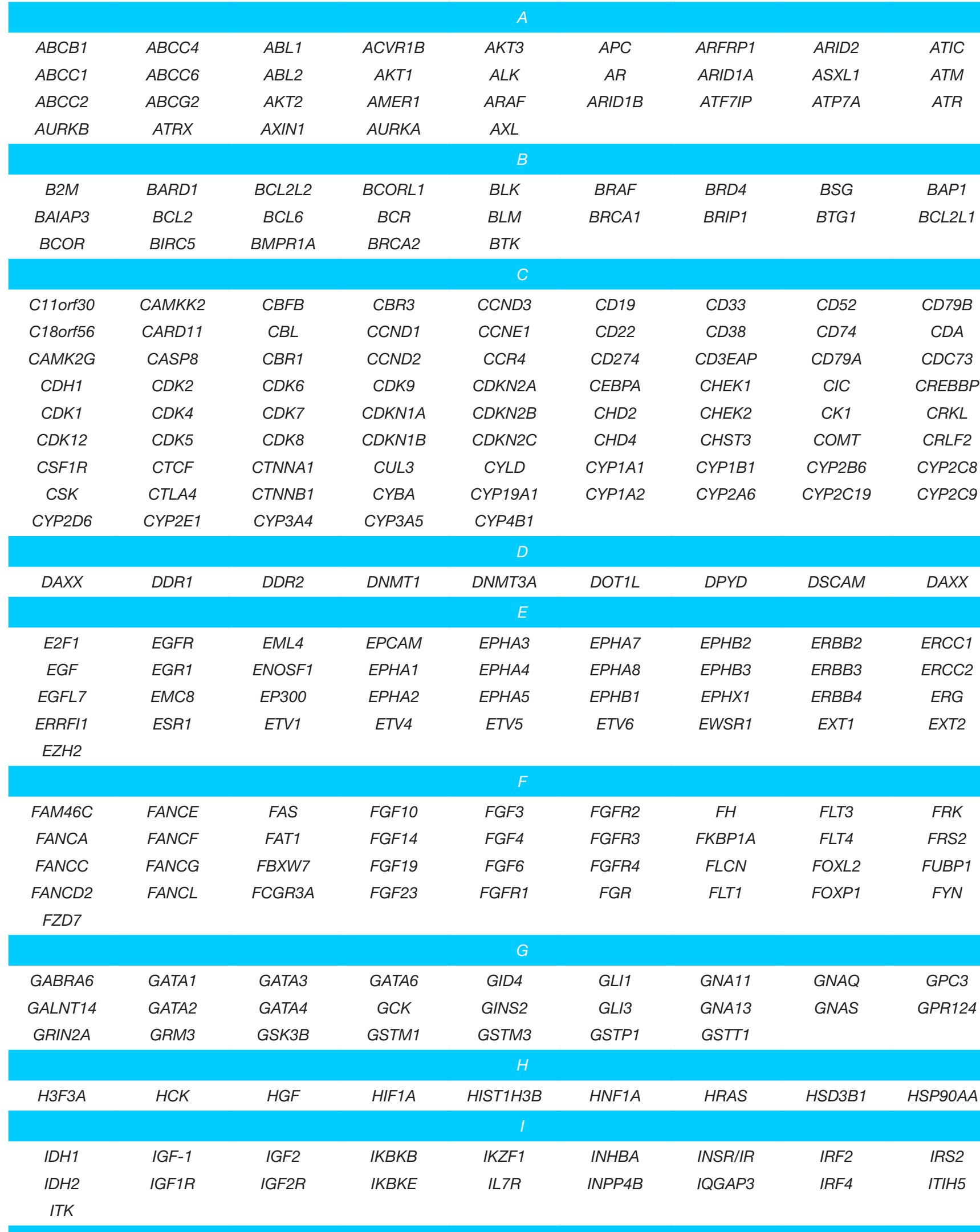



$\begin{array}{llll}\text { PAK2 PTPN11 PTPRD } & \text { PTKG } & & \\ & & & \\ & & \end{array}$

\begin{tabular}{|c|c|c|c|c|c|c|c|c|}
\hline \multicolumn{9}{|c|}{$R$} \\
\hline RAC1 & RAD5O & RAD51C & RAF1 & RARA & RBM10 & RHPN2 & RMDN2 & ROCK1 \\
\hline RAC2 & RAD51 & RAD51D & RANBP2 & $R B 1$ & RET & RICTOR & RNF43 & MSTIR \\
\hline & & RPSGKA1 & RPSGKB1 & RPTOR & RRM1 & RUNX1 & RUNXIT1 & \\
\hline \multicolumn{9}{|c|}{$s$} \\
\hline & SDHD & SKP2 & SLC22AG & SMAD4 & SOD2 & SPOP & STAT1 & STAT6 \\
\hline SDHA & SETD2 & SLC10A2 & SLCO1B1 & SMARCA4 & $50 \times 10$ & SPTA1 & STAT2 & STEAPI \\
\hline SDHAF 1 & $S F 3 B 1$ & SLC15A2 & SLCO1B3 & SMARCB1 & sox2 & $S R C$ & STAT3 & STK11 \\
\hline SDHAF2 & SGK1 & SLC22A1 & SLIT2 & SMO & soxg & SRD5A2 & STAT4 & STK3 \\
\hline SDHB & SHH & SLC22A16 & SMAD2 & SNCAIP & SPEN & SRMS & STAT5A & STK4 \\
\hline SDHC & SIK1 & SLC22A2 & SMAD3 & socs1 & SPG7 & STAG2 & STAT5B & SUFU \\
\hline SULTIAT & SULTIA2 & SULTTC4 & & & & & & \\
\hline
\end{tabular}

$\begin{array}{ccccccccc}\text { TAF1 } & \text { TCF7L2 } & \text { TNF } & \text { TNFRSF8 } & \text { TET2 } & \text { TK1 } & \text { TOP1 } & \text { TPMT } & \text { TSC1 } \\ \text { TBX3 } & \text { TEK } & \text { TNFAIP3 } & \text { TNFSF11 } & \text { TGFBR1 } & \text { TMEM127 } & \text { TOP2A } & \text { TPX2 } & \text { TSC2 } \\ \text { TCFL1 } & \text { TERT } & \text { TNFRSF14 } & \text { TNFSF13B } & \text { TGFBR2 } & \text { TMPRSS2 } & \text { TP53 } & \text { TYRO3 } & \text { TYMS } \\ \text { TSHR } & \text { TNK2 } & \text { TNFRSF10B } & \text { TNFRSF10A } & & & & & \end{array}$
TSHR TNK2 TNFRSF10B TNFRSF10A

$\begin{array}{llllllll}\text { U2AF1 UBE2I UGT1A1 UGT2B15 } & \text { UGT2B17 } & \text { UGT2B7 } & \text { UMPS } & \text { U2AF1 } & \text { UBE21 }\end{array}$

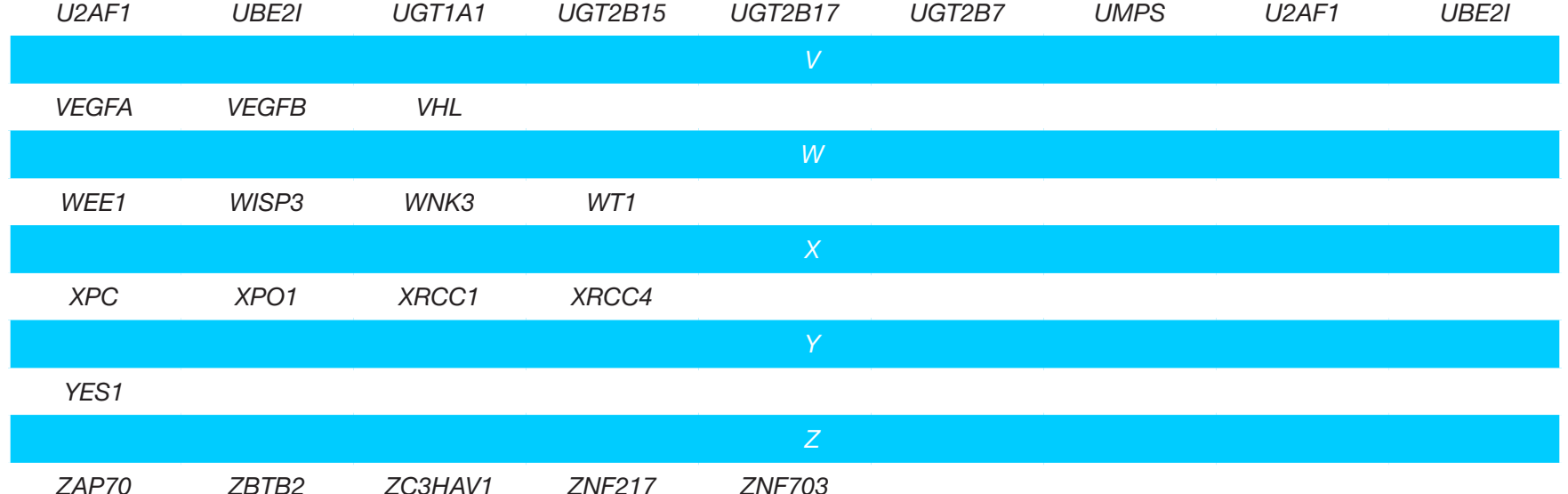

$\begin{array}{llll}\text { ZBTB2 } & \text { ZC3HAV1 } & \text { ZNF217 } & \text { ZNF703 }\end{array}$

Figure S1 Next-generation sequencing to identify mutations in 549 tumor-related genes 